\title{
Desarrollo normativo y de política pública contra el abuso sexual infantil en Colombia
}

\author{
Regulatory development and public policy against child sexual abuse in Colombia \\ Desenvolvimento regulatório e políticas públicas contra o abuso sexual infantil na Colômbia
}

DOI: https://doi.org/10.21803/penamer.13.26.426

Adelaida María Ibarra Padilla https://orcid.org/0000-0002-4921-1664

Ricardo Omar Lora Ramírez https://orcid.org/0000-0001-5211-0357

Yolanda Cecilia Preciado Gómez https://orcid.org/0000-0001-9316-5485

\section{¿Cómo citar este artículo?}

Ibarra, A., Lora, R. \& Preciado, Y. (2020). Desarrollo normativo y de política pública contra el abuso sexual infantil en Colombia. Pensamiento Americano, 13(26), 139-151

DOI: https://doi.org/10.21803/penamer.13.26.426

\section{Resumen}

El abuso sexual contra niñas, niños y adolescentes es una modalidad de maltrato grave que trasgrede la libertad sexual y la dignidad humana y puede ocasionar afectaciones físicas y psicológicas a la víctima. El presente artículo analiza el desarrollo normativo del tema en Colombia y las medidas de política pública implementadas en el país para su prevención y remedio. Para lograr este cometido se estudiaron los instrumentos de Derecho Internacional Público sobre esta problemática insertos en el derecho doméstico. Asimismo, se analizan las medidas que vienen implementando las autoridades competentes como la Policía Nacional y el Instituto Colombiano de Bienestar Familiar (ICBF), asimismo la labor que frente al tema realizan los establecimientos educativos. Se concluye que esta problemática requiere de un abordaje interdisciplinario y multidimensional. El estudio arroja que las medidas vigentes en la materia son en su mayoría de carácter sancionatorio y reparador, pero pocas de carácter preventivo. La prevención de este flagelo requiere de medidas de salud mental, educación sexual, acompañamiento psicosocial a las familias en pobreza extrema y el trabajo articulado entre las familias, los colegios y las autoridades competentes.

Palabras clave: Abuso sexual infantil, Maltrato infantil, Abusador sexual, Víctima, Políticas públicas.

\begin{abstract}
Sexual abuse against children and adolescents is a form of serious abuse that violates sexual freedom and human dignity and can cause physical and psychological harm to the victim. This article analyzes the regulatory development of the subject in Colombia and the public policy measures implemented in the country for its prevention and remedy. To achieve this goal, the instruments of Public International Law on these issues inserted in domestic law were studied. Likewise, the measures that are being implemented by the competent authorities such as the National Police and the Colombian Institute of Family Welfare (ICBF) are analyzed, as well as the work that educational establishments do on the subject. It is concluded that this problem requires an interdisciplinary and multidimensional approach. The study shows that the measures in force on the matter are mostly of a sanctioning and reparative nature, but few of a preventive nature. The prevention of this scourge requires mental health measures, sexual education, psychosocial support to families in extreme poverty and the articulated work between families, schools and the competent authorities.
\end{abstract}

Keywords: Child sexual abuse, child maltreatment, sex offender, victim, public policy. 


\section{Resumo}

O abuso sexual contra meninas, meninos e adolescentes é uma forma de maus-tratos graves que viola a liberdade sexual e a dignidade humana e pode causar danos físicos e psicológicos à vítima. Este artigo analisa o desenvolvimento regulatório do tema na Colômbia e as medidas da política pública implementadas no país para sua prevenção e remediação. Para tanto, foram estudados os instrumentos de Direito Internacional Público sobre esta problemática inseridos no direito interno. Da mesma forma, são analisadas as medidas que vêm sendo implementadas pelas autoridades competentes, como a Polícia Nacional e o Instituto Colombiano de Bem-Estar da Família (ICBF), bem como o trabalho realizado por estabelecimentos de ensino sobre o tema. Conclui-se que este problema requer uma abordagem interdisciplinar e multidimensional. $O$ estudo mostra que as medidas em vigor na matéria são maioritariamente punitivas e reparadoras, mas poucas de carácter preventivo. A prevenção deste flagelo requer medidas de saúde mental, educação sexual, apoio psicossocial às famílias em situação de extrema pobreza e trabalho articulado entre famílias, escolas e órgãos competentes.

Palavras-chave: Abuso sexual infantil, abuso infantil, abusador sexual, vítima, políticas públicas.

\section{Perfil}

Docente Tiempo Completo de la Universidad Militar Nueva Granada. adelaida. ibarra@unimilitar.edu.co.
Adelaida María Ibarra Padilla Doctora

Ricardo Omar Lora Ramírez Abogado

Yolanda Preciado Gómez Abogada

ypreciado2010@hotmail.com. 


\section{Introducción}

El abuso sexual es una de las manifestaciones más de maltrato infantil ${ }^{l}$ dados sus efectos físicos y psicológicos en la víctima. De acuerdo con la OMS (2009, p. 11), en el mundo el $20 \%$ de las mujeres y del $5 \%$ al $10 \%$ de los hombres afirman haber sufrido abuso sexual durante la niñez. En Colombia, entre 2014 y 2017, un total de 32.106 menores entre los 6 y los 17 años víctimas de abuso sexual tomaron parte en procesos administrativos de restablecimiento de derechos; de estos 27.784 eran de género femenino y 4.322 de género masculino (Presidencia de la República, 2018, p. 17).

En el año 2016, el Instituto Nacional de Medicina Legal y Ciencias Forenses llevó a cabo un total de 21.399 valoraciones médico legales a nivel nacional por presuntas violaciones a la integridad sexual; de estas, 18.41, es decir, el 86,06\%, corresponden a niños, niñas y adolescentes (Ricaurte, 2016). En el año 2017 dicho instituto practicó 23.798 exámenes por este mismo delito. De estos, 20.663 casos, es decir, el 86,83\% corresponden a menores de edad. El 85,4\% de las víctimas eran de género femenino (Canesto, 2017). En el 2018, se presentaron 26.065 casos de delito sexual; 22.794 casos, equivalente al 87,45\% corresponde a niños, niñas y adolescentes. La mayor tasa se presenta entre los menores de 10 a 13 años (Cifuentes, 2018). Estos datos estadísticos evidencian que en Colombia las principales víctimas de agresiones de tipo sexual son los menores de edad.

Este artículo analiza la política pública de prevención y tratamiento del abuso sexual infantil que se viene implementando en el país. Para lograr este cometido se realizó un estudio con enfoque descriptivo, diseño cualitativo, y fuentes secundarias como literatura científica especializada y documentos oficiales como informes anuales del Instituto Nacional de Medicina Legal y Ciencias Forenses y el ICBF y el Plan Nacional de Desarrollo 2018-2022. El presente trabajo incluye también el análisis de diversas fuentes doctrinales y del marco normativo internacional y nacional frente al abuso sexual infantil.

El artículo se encuentra dividido en tres partes. La primera se ocupa de las generalidades del abuso sexual infantil incluyendo, su definición, los principales factores asociados a la ocurrencia de este fenómeno, sus diferentes tipos y la clasificación y caracterización de los abusadores sexuales desde la psicología. La segunda parte expone el marco normativo nacional e internacional que protege los derechos de los niños frente a este delito. La tercera presenta las medidas de prevención de la violencia sexual infantil que vienen adelantado diferentes entidades públicas del orden nacional responsables del tema. Por último, se exponen a manera de conclusión las fortalezas y aspectos a mejorar de la política pública colombiana contra el abuso sexual infantil.

\section{ASPECTOS GENERALES DEL ABUSO SEXUAL INFANTIL}

\subsection{DEFINICIÓN DE ABUSO SEXUAL IN- FANTIL}

La OMS define el abuso sexual infantil (ASI) como "la participación de un niño en actividades sexuales que no comprende plenamente, en las que no puede consentir con conocimiento de causa o para las que no está suficientemente desarrollado, o que transgreden leyes o tabúes sociales" (OMS, 2009, p. 10). Por medio de actos abusivos o impuestos, el agresor persigue llenar sus necesidades sexuales inmaduras e insatisfechas. Con frecuencia el abuso es precedido de dádivas y juegos seductores que colocan a la víctima en una situación ambivalente (Almonte, Insunza \& Ruiz, 2002, p. 22).

Las estrategias más comúnmente utilizadas por los agresores son la persuasión y el engaño, las amenazas, la sorpresa, la aproximación y la confianza, y la familiaridad. Con frecuencia, el agresor seduce al menor por medio de regalos y manipulándolo emocionalmente. El abuso tiene lugar después de un proceso de preparación luego de que el agresor se ha ganado la

\footnotetext{
1 Por maltrato infantil se entiende "el maltrato fisico y emocional, el abuso sexual, la desatención y el tratamiento negligente de los niños, así como su explotación con fines comerciales o de otro tipo" (OMS, 2009, p. 7). En el ordenamiento jurídico colombiano la Ley 1098 (2006, art 18) define el maltrato infantil "toda forma de perjuicio, castigo, humillación o abuso físico o psicológico, descuido, omisión o trato negligente, malos tratos o explotación sexual, incluidos los actos sexuales abusivos y la violación y en general toda forma de violencia o agresión sobre el niño, la niña o el adolescente por parte de sus padres, representantes legales o cualquier otra persona".
}

Pensamiento Americano Vol. 13 - No. 26 - p.p. 139- 151 - 2020 • Julio-Diciembre · Corporación Universitaria Americana · Barranquilla, Colombia · ISSN: $2027-2448$ http://publicaciones.americana.edu.co/index.php/pensamientoamericano/index 
confianza de su víctima. La violencia física solamente aparece en un 10-14\% de los casos (Lameiras, Carrera, \& Failde, 2008, p. 12).

Las consecuencias de esta forma de violencia comprenden desde cambios en la conducta, hasta la aparición de trastornos emocionales que pueden ser temporales o perdurar hasta la vida adulta (Isaza, Alzate \& Santander, 2007). Un estudio realizado en Santiago de Chile sobre esta problemática arrojó que los menores que sufrieron abuso sexual presentan ansiedad y depresión, acompañado de episodios de estrés postraumático. En ellos "prevalecen sentimientos de indefensión, desamparo, desconfianza y temor como consecuencia de la agresión experimentada" (Gómez, Cifuentes \& Sieverson, 2010, p. 10).

\subsection{PRINCIPALES FACTORES DE RIESGO ASOCIADOS AL ABUSO SEXUAL INFANTIL}

Gonzaga (2015), clasifica los factores de riesgo asociados al abuso sexual infantil en individuales, familiares y sociales. Los individuales están asociados a los rasgos innatos de personalidad que son condicionados por el ambiente en el que se desenvuelve, la historia personal y su relación con sus padresy sus experiencias de infancia, especialmente las traumáticas. Los factores familiares asociados al ASI son las características del lugar de habitación, el tipo de estructura familiar, la calidad de la relación entre los miembros de la familia y las redes de apoyo que tenga la familia. Los factores sociales de riesgo se refieren a las variables socio-económicas, socio-ambientales y culturales que determinan los atributos, jerarquías, símbolos y valores que las sustentan interacciones al interior de un grupo.

Otros factores de riesgo de ASI son que el cabeza de hogar sea alcohólico o adicto a las drogas, tenga un nivel socioeconómico bajo, habite en condiciones de hacinamiento, en barrios en situación de pobreza y carezca de empleo o fuente de ingreso estable (Acuña, 2014).

Pertenecer al género femenino constituye una condición que aumenta significativamente el riesgo de ser víctima de violencia sexual. Según cifras publicadas en la "Política Marco de Convivencia y Seguridad Ciudadana” (Presidencia de la República, 2019), en el año 2018 , el $12 \%$ de los menores víctima de delitos sexuales eran de género masculino, mientras que el $88 \%$ eran de género femenino. Según cifras de Medicina Legal, de ese mismo año, por cada niño víctima de presunto delito sexual entre los 10 y 13 años se presentaron ocho niñas. Como consecuencia de esta forma de violencia 5.713 menores resultaron embarazadas (Cifuentes, 2018). Las raíces de la violencia contra la mujer, se hallan en la inequidad de género y "los desequilibrios históricos y estructurales de poder entre mujeres y hombres existentes en variados grados a lo largo de todas las comunidades en el mundo" (ONU Mujeres, 2010).

\subsection{MODALIDADES DE ABUSO SEXUAL IN- FANTIL}

El abuso sexual infantil abarca un amplio espectro de relaciones y comportamientos desde sutiles hasta violentos. El abuso sexual puede presentarse con y sin contacto. El primero conlleva el contacto físico, bien sea genital, oral, o por cualquier otra parte del cuerpo con la finalidad de obtener satisfacción sexual. Esta modalidad de abuso incluye caricias, tocamientos, penetración genital, anal, entre otras.

Corresponden a la modalidad de abuso sexual sin contacto la exhibición erótica, la masturbación del agresor delante del menor, espiar al menor cuando este se viste o baña, exponerle material pornográfico, hacerle comentarios o llamadas telefónicas de contenido sexual.

Según la relación existente entre el menory suagresor el abuso sexual puede ser intra o extrafamiliar. En el abuso sexual intrafamiliar, el agresor es un miembro de la familia, el cual, valiéndose de su parentesco y de situación de poder propicia situaciones y realiza acciones para manipular a la víctima (Barudy, 1998)

El abuso sexual intrafamiliar ocurre en la intimidad familiar y presenta una serie de estadios. En el primer estadio se encuentran varias fases. La primera es la fase de seducción; en esta el agresor se dedica a ga-

Pensamiento Americano Vol. 13 - No. 26 - p.p. 139- 151 • 2020 • Julio-Diciembre · Corporación Universitaria Americana • Barranquilla, Colombia • ISSN: 2027-2448 http://publicaciones.americana.edu.co/index.php/pensamientoamericano/index 
narse la confianza del niño. La fase del abuso es en la que se llevan a cabo las conductas abusivas que suelen ser progresivas iniciando como juegos inocentes y van incrementando gradualmente. La fase del silencio es aquella en la que el agresor se asegura de que la víctima no le delate (Gil \& De Manuel, 2019, p. 272).

El segundo estadio consta, a su vez, dos fases: fase de desvelamiento del secreto y fase represiva. La fase de desvelamiento del secreto se presenta cuando la víctima logra superar los sentimientos de culpabilidad, vergüenza y miedo y divulga los hechos incestuosos. En la fase represiva se caracteriza por "la descalificación del discurso y de la persona de la víctima, las acusaciones que tienden a señalar a la víctima como culpable o la negación de las evidencias de los hechos" (Barudy, 1998, p. 214).

El abuso sexual infantil extrafamiliar tiene lugar cuando el acto abusivo es llevado a cabo por una persona que no hace parte del grupo familiar, ya sea un desconocido o alguien conocido, e incluso cercano, pero con el cual no exista parentesco. En este último caso, el agresor aprovecha la confianza que han depositado en él los familiares de la víctima para lograr su cometido. En la mayoría de los casos no se recurre a la violencia ya que cuenta con el tiempo para aproximarse a su víctima, seducirla y someterla. Esta modalidad de abuso suele realizarse de forma secreta, gradual y sin resistencia.

Por último, se encuentra el caso en el cual el agresor es un completo desconocido. Aquí el victimario no cuenta con el tiempo necesario para ganarse la confianza de su víctima por tanto esta presta resistencia y el agresor recurre a la fuerza y la violencia para someterla.

\subsection{CARACTERÍSTICAS MÁS FRECUEN- TES ENTRE ABUSADORES SEXUALES IN- FANTILES}

Según la OMS, los menores pueden "ser objeto de abusos sexuales por parte de adultos o de otros niños que, o en razón de su edad o de su estado de desarrollo, estén en una situación de responsabilidad, confianza o poder en relación con su víctima” (OMS, 2009, p. 10).

Si bien no todos los abusadores presentan las mismas características, sí existen algunos patrones comunes dentro de estos. Soria y Hernández (1994), clasifican los abusadores sexuales en: inmaduros, regresivos y agresivos. Los inmaduros son individuos que por lo general tienen una edad emocional muy inferior a su edad cronológica. Estos abusadores son también llamados "exclusivos" ya que no están en capacidad de relacionarse afectivamente con personas adultas. El abuso sexual de los pequeños con frecuencia se comete sin resistencia por parte de estos. El agresor suele escoger a "menores que sufren de carencias afectivas y mediante un trato cariñoso y cooperador, consiguen que las víctimas ansíen verlos y disfruten de su compañía” (Soria \& Hernández, 1994, p. 102).

Los abusadores regresivos presentan generalmente dificultades para enfrentar sus problemas. Se caracterizan por no tener en sí una inclinación sexual por los menores, sino que lo hacen en momentos de ansiedad para mitigar su tensión al poder dominar a su víctima. Estos abusadores, también llamados "no exclusivos" usualmente su orientación sexual es hacia personas de la misma edad, sin embargo, ante situaciones de mucho estrés su preferencia sexual varía transitoriamente (Soria \& Hernández, 1994).

Los abusadores agresivos se caracterizan por tener un comportamiento sexual impulsivo y cargado de ira. Suelen ocasionar lesiones a sus víctimas e incluso la muerte, ya que estas constituyen el objeto odiado, depositando en estas su agresividad. Este tipo de abusador tiene personalidad psicopática, conducta antisocial sin grado mínimo de empatía (Soria \& Hernández, 1994, p. 102).

Los abusadores suelen justificar su conducta y desplazar su responsabilidad hacia las víctimas. Las víctimas son señaladas de ser las seductoras, provocadoras o enloquecedoras. También es frecuente que el agresor culpe a su pareja del abuso basándose en el argumento de que la negativa de tener relaciones sexuales o la falta de atención o afecto los empujaron a llevar a cabo 
el abuso del menor. Otros se excusan en que el hecho abusivo solo se dio solo una vez y que no saben lo que les pasó. Algunos sostienen que la conducta sexual abusiva era su manera de demostrar cercanía y afecto a niñas o niños carentes del mismo (González, Martínez, Leyton \& Bardy, 2004).

\section{MARCO NORMATIVO EN MATERIA DE ABUSO SEXUAL INFANTIL}

\subsection{DERECHOS DEL NIÑO EN EL DERECHO INTERNACIONAL PÚBLICO}

La Declaración Universal de Derechos Humanos (ONU, 1948, art. 1) reconoce la existencia de una serie de derechos innatos e inalienables a todo ser humano sin distinción alguna, incluyendo a los menores. El artículo tercero de dicha Declaración sostiene que: “Todo individuo tiene derecho a la vida, a la libertad y a la seguridad de su persona”. El abuso sexual transgrede la seguridad y la libertad sexual de los menores. Esta forma de violencia también vulnera el derecho a la salud ya que suele venir acompañada de lesiones físicas, psicológicas y la trasmisión de diferentes enfermedades.

La Convención sobre los Derechos del Niño (1989) el primer instrumento universal de carácter vinculante para la protección de los menores. La Convención consagra el deber de los Estados firmantes de adoptar "todas las medidas legislativas, administrativas, sociales y educativas apropiadas para proteger al niño contra toda forma de perjuicio o abuso físico o mental, descuido o trato negligente, malos tratos o explotación, incluido el abuso sexual" (ONU, 1989, art. 19).

Como complemento de dicho instrumento se encuentra el "Protocolo Facultativo sobre la venta de niños, la prostitución infantil y la utilización de niños en la pornografía”, el cual establece para las Partes el deber de brindar servicios jurídicos y el apoyo sicológico, médico, financiero y logístico que requieran los menores víctimas para su rehabilitación.

El "Convenio 182 sobre sobre las peores formas de trabajo infantil” de la Organización Internacional del
Trabajo, por su parte, obliga a los Estados Parte a modificar su legislación doméstica a fin de proteger a los menores contra estos tipos de trabajo. Entre las peores formas de trabajo infantil la convención señala "(b) la utilización, el reclutamiento o la oferta de niños para la prostitución, la producción de pornografía o actuaciones pornográficas" (OIT, 1999, art. 3).

El más reciente instrumento internacional en la materia es el "Protocolo Facultativo de la Convención sobre los Derechos del Niño relativo a la venta de niños, la prostitución infantil y la utilización de los niños en la pornografía” (2000) hace un llamado a los Estados a criminalizar y castigar estos delitos. Este plantea además el castigo no solo de aquellos que ofrezcan menores para la explotación sino también de toda persona que utilice menores para desarrollar tales actividades.

\subsection{EL ABUSO SEXUAL INFANTIL EN EL DERECHO DOMÉSTICO}

La adopción dela Constitución Política (1991) constituye un hito en la garantía y la defensa de los derechos de los niños, niñas y adolescentes en el ordenamiento jurídico colombiano al consagrar a Colombia como estado social de derecho. El artículo 44 constitucional señala que los menores "Serán protegidos contra toda forma de abandono, violencia física o moral, secuestro, venta, abuso sexual, explotación laboral o económica y trabajos riesgosos”.

La Ley 679 de 2001 se constituye en el primer instrumento de orden legal "para prevenir y contrarrestar la explotación, la pornografía y el turismo sexual con menores" en el país. En ella se establecen las responsabilidades de las distintas autoridades públicas y entidades privadas en la sensibilización, prevención, monitoreo y sanción de dicho flagelo.

En el año 2006 se aprueba el Código de la Infancia y la Adolescencia (Ley 1098, 2006). Este tiene por objeto "la protección integral de los niños, las niñas y los adolescentes, garantizar el ejercicio de sus derechos y libertades consagrados en los instrumentos internacionales de derechos humanos, en la Constitución

Pensamiento Americano Vol. 13 - No. 26 - p.p. 139- 151 • 2020 • Julio-Diciembre · Corporación Universitaria Americana • Barranquilla, Colombia • ISSN: 2027-2448 http://publicaciones.americana.edu.co/index.php/pensamientoamericano/index 
Política y en las leyes, así como su restablecimiento" (Ley 1098, 2006, art. 2). El código se orienta por los principios del interés superior ${ }^{2}$, la corresponsabilidad de la familia, el Estado y la sociedad en la protección, atención y cuidado, y la prevalencia de los derechos de menores.

En todo acto, decisión o medida administrativa, judicial o de cualquier naturaleza que deba adoptarse en relación con los niños, las niñas y los adolescentes, prevalecerán los derechos de éstos, en especial si existe conflicto entre sus derechos fundamentales con los de cualquier otra persona. En caso de conflicto entre dos o más disposiciones legales, administrativas o disciplinarias, se aplicará la norma más favorable al interés superior del niño, niña o adolescente. (Ley 1098, 2006, art. 9)

Mediante el Decreto 4690 de 2007 surge la "Comisión Intersectorial para la Prevención del Reclutamiento, la Utilización y la Violencia Sexual contra Niños, Niñas y Adolescentes por Grupos Armados al Margen de la ley y por Grupos Delictivos Organizados" (CIPRUNNA), con el fin de diseñar, coordinar y evaluar los proyectos, programas, estrategias y políticas para la prevención de las problemáticas antes señaladas en el ámbito territorial con enfoque de protección integral.

En materia penal se observa una clara tendencia hacia el endurecimiento de las penas por delitos sexuales contra niños, niñas y adolescentes. Así, el código penal colombiano (Ley 599, 2000) contemplaba en un principio para el tipo penal de "Acceso carnal abusivo con menor de catorce años” (art. 208) una pena privativa de la libertad de 4 a 8 años, y para el de "Actos sexuales con menor de catorce años" una pena de prisión de 48 a 90 meses. Con la Ley 890 de 2004 que modifica el código penal, la pena por "Acceso carnal abusivo con menor de catorce años" pasa a ser de 64 a 144 meses de prisión y el de "Actos sexuales con menor de catorce años” de 48 a 90 meses. Luego, mediante la Ley 1236 de 2008, se incrementan nuevamente las penas para estos delitos llegando a ser de 12 a 20 años en el caso de "Actos sexuales con menor de catorce años" y de 9 a 13 años para "Actos sexuales con menor de catorce años". Asimismo, contempla como circunstancia de agravación punitiva del tipo penal de acceso carnal violento, que se realice sobre persona menor de 14 años (art. 211). En junio de 2020, el congreso aprobó un polémico proyecto de Ley que establece la posibilidad de imponer hasta la cadena perpetua cuando se presente acceso carnal violento contra niño, niña o adolescente.

La Ley 1146 de 2007 tiene por objeto la prevención y atención integral del abuso sexual infantil ${ }^{3}$. Para ello, la ley contempla el "Comité Interinstitucional Consultivo para la Prevención de la Violencia Sexual y Atención Integral de los Niños, Niñas y Adolescentes Víctimas del Abuso Sexual”, al cual le asigna la tarea de articular, asesorar y apoyar a las entidades públicas en la lucha contra el ASI. Asimismo, crea la "Cátedra de educación para la sexualidad” la cual debe ser incluida en los programas de estudio en los establecimientos educativos con el fin de contribuir a la prevención del abuso sexual infantil.

La Ley 1336 de 2009, que adiciona la Ley 679 de 2001, busca robustecer la lucha contra la explotación, la pornografía y el turismo sexual de menores, asignando para ello funciones específicas en la materia al Ministerio de Comercio, Industria y Turismo y al ICBF.

Si bien se ha logrado demostrar que "los niños pueden dar testimonios altamente precisos de cosas que han presenciado o experimentado, especialmente si para ellos son personalmente significativos o emocionalmente remarcables" (Berlinerblau \& Taylor, 2003, p. 34), el hecho de que el menor víctima tenga que testificar en el juicio oral contra su agresor puede conllevar su revictimización al verse obligado a revivir la experiencia traumática que afrontó. Por ello, la Ley 1652 de

2 "Se entiende por interés superior del niño, niña y adolescente, el imperativo que obliga a todas las personas a garantizar la satisfacción integral y simultánea de todos sus derechos humanos, que son universales, prevalentes e interdependientes" (Ley 1098, 2006, art. 8).

3 En el año de expedición de esta ley, el número de exámenes sexológicos realizados por Medicina Legal por presunto abuso sexual en menores de edad fue de 15.353, que correspondía al $85,7 \%$ del total de pruebas realizadas, siendo las niñas las más afectadas. “Por cada niño, se atienden 6 niñas y por cada persona adulta se atienden 3,1 menores de edad, lo que evidencia la problemática tan grave contra la niñez (González, 2007, p. 145)

Pensamiento Americano Vol. 13 - No. 26 - p.p. 139- 151 • 2020 • Julio-Diciembre • Corporación Universitaria Americana • Barranquilla, Colombia • ISSN: 2027-2448 http://publicaciones.americana.edu.co/index.php/pensamientoamericano/index 
2013 establece cómo deben tomarse el testimonio y la entrevista a menores que participen en procesos penales por delitos contra la integridad y libertad sexuales.

La entrevista forense de niños, niñas o adolescentes víctimas de violencia sexual será realizada por personal del Cuerpo Técnico de Investigación de la Fiscalía General de la Nación, entrenado en entrevista forense en niños, niñas y adolescentes, previa revisión del cuestionario por parte del Defensor de Familia, sin perjuicio de su presencia en la diligencia (Ley 1652, 2013, art. 2, lit. b)

Así mismo, la ley establece que los menores víctimas de conductas contra la integridad sexual preferiblemente deberán ser entrevistados solo una vez, lo que implica que estas versiones brindadas con anterioridad al juicio oral "puedan ser admitidas como prueba de referencia, con lo que se evita su presencia en la fase de juzgamiento y, con ello, que el trámite procesal se convierta en otro escenario de victimización”. (Sentencia SP2709-2018).

Por último, la Ley 1918 de 2018 contempla un régimen de inhabilidades para aquellos individuos hallados responsables de cometer delitos contra la integridad, libertad y formación sexuales de niños, niñas y adolescentes para acceder a cargos o profesiones que impliquen contacto directo y frecuente con menores de edad.

\section{POLÍTICAS PÚBLICAS CONTRA EL ABU- SO SEXUAL INFANTIL EN COLOMBIA}

\subsection{MEDIDAS ADOPTADAS POR EL ICBF CONTRA EL ABUSO SEXUAL INFANTIL}

El ICBF, como ente rector del Sistema Nacional de Bienestar Familiar (SNBF)4, es el responsable de propender por el bienestar de las familias y llevar a cabo la política pública en materia de prevención y protección integral de los menores, en especial de aquellos cuyos derechos se encuentran en situación de riesgo.
El capítulo tercero del Código de la Infancia y la Adolescencia señala a las Defensorías de Familia como las dependencias del ICBF a cargo de prevenir, garantizar y restablecer los derechos de los niños, niñas y adolescentes que se encuentren en situación de amenaza o violación a sus derechos. Para ello se conforman grupos interdisciplinarios integrados por un psicólogo, un nutricionista y un trabajador social. Entre las facultades que le reconoce la Ley 1098 (2006, art. 106) al Defensor y al Comisario de Familia se halla llevar a cabo allanamientos a sitios donde niños, niños y adolescentes pudiesen estar en riesgo, para lo cual podrán contar con el apoyo de la fuerza pública.

La Dirección de la Niñez y Adolescencia del ICBF adelanta programas de promoción de derechos y prevención del abuso sexual dentro de los cuales se encuentra el programa "Generaciones con Bienestar”. Esta medida promueve la participación activa de los niños, niñas y adolescentes al tiempo que contribuye a la prevención temprana a través de la construcción de entornos protectores familiares, comunitarios e institucionales en el país.

Adicionalmente se encuentra el programa "Construyendo Juntos Entornos Protectores” el cual busca

Promover los derechos de la infancia y la adolescencia, prevenir las vulneraciones de los mismos y fortalecer los vínculos de cuidado mutuo y la convivencia armónica, a través de espacios de información, formación y reflexión entre padres, madres, cuidadores, docentes, agentes educativos y, por supuesto, niños, niñas y adolescentes (ICBF, 2018, p. 17).

Las modalidades de atención que brinda el ICBF se clasifican en "apoyo y fortalecimiento de la familia" y "apoyo y fortalecimiento en medio diferente al de la familia de origen o red vincular". En el primer caso, la Ley 1098 de 2006 (art. 107, parágrafo) prevé que el Defensor de Familia puede disponer que los

4 El SNBF "es el conjunto de agentes, instancias de coordinación y articulación y de relaciones existentes entre estos para dar cumplimiento a la protección integral de los niños, niñas y adolescentes y el fortalecimiento familiar en los ámbitos nacional, departamental, distrital, municipal" (Decreto 936, 2013, art. 2).

Pensamiento Americano Vol. 13 - No. 26 - p.p. 139- 151 • 2020 • Julio-Diciembre · Corporación Universitaria Americana • Barranquilla, Colombia • ISSN: 2027-2448 http://publicaciones.americana.edu.co/index.php/pensamientoamericano/index 
padres o personas a cargo del menor víctima o en situación de riesgo cumplan con actividades tales como la asistencia a programas de orientación familiar, de tratamiento contra el alcoholismo o la drogadicción, terapias psicológicas, entre otras actividades tendientes a garantizar que la familia sea un entorno seguro para este. En el segundo caso, se podrá disponer que el menor sea remitido a un internado de atención especializada o a un hogar sustituto.

\subsection{MEDIDAS ADOPTADAS POR LA POLI- CÍA NACIONAL CONTRA EL ABUSO SEXUAL INFANTIL}

La Policía Nacional es miembro del SNBF y tiene como objetivo garantizar la protección integral de los menores para lo cual cuenta con la unidad especializada "Policía de Infancia y Adolescencia". Esta es la encargada de velar por el cumplimiento de los derechos de los niños, niñas y adolescentes envueltos en procesos judiciales. Asimismo, adelanta campañas de prevención, garantía y restablecimiento de derechos de los menores en todo el país.

En el año 2010, la Policía de Infancia y Adolescencia crea el programa "Abre tus ojos", el cual tiene por finalidad identificar y combatir los factores de riesgo a que están expuestos los menores en los entornos donde se desenvuelven. Para lograr dicho objetivo, el programa cuenta con actividades educativas y lúdicas que incluyen cine foros donde se proyectan videos o películas con el fin de sensibilizar a la comunidad sobre esta problemática.

La puesta en escena de dramatizaciones y obras de teatro es otra de las estrategias educativas que adelanta la Policía de Infancia y Adolescencia. Estas obras suelen presentarse en colegios, parques, terminales, entre otros. También se encuentran buses interactivos que recorren el territorio nacional para dar a conocer a la comunidad sobre la problemática del ASI. En estos buses interactivos, los menores y la comunidad en general pueden conocer los principales aspectos de la problemática, los riesgos asociados a esta y la forma de prevenirla.
En el año 2019, la Policía Nacional emprende la campaña de prevención "Ojos en todas partes”, la cual tiene por objetivo sensibilizar a la ciudadanía respecto al delito de explotación sexual-comercial de niños, niñas y adolescentes. Esta campaña se llevó a cabo con el apoyo del Ministerio de Comercio Industria y Turismo en lugares turísticos de las ciudades principales del país y en redes sociales e invita a la comunidad a denunciar la presencia de redes o personas dedicadas a la explotación sexual de menores.

\subsection{EL PAPEL DEL SECTOR EDUCACIÓN EN LA PREVENCIÓN DEL ABUSO SEXUAL IN- FANTIL}

Las instituciones educativas juegan un papel preponderante en la prevención, detección e intervención del ASI. En primera instancia por su labor de formación y sensibilización de los niños, niñas y adolescentes con relación a su sexualidad y al ASI atendiendo al nivel de desarrollo psicológico, social y biológico de estos. En segunda instancia, todos los docentes y administrativos del establecimiento educativo deben denunciar cualquier situación de abuso sexual de la que tengan conocimiento.

Cada institución educativa está llamada a desarrollar programas de prevención contra el ASI donde se les enseñe a los menores acerca de cómo proteger su cuerpo, cuándo pueden ser víctimas de abuso sexual, y cuáles son los factores de riesgo. En las escuelas para padres se hace igualmente charlas de sensibilización a los padres de familia sobre el tema.

Mediante la Ley 1620 del 2013 se creó el "Sistema nacional de convivencia escolar y formación para el ejercicio de los derechos humanos, la educación para la sexualidad y la prevención y mitigación de la violencia escolar". Esta normativa contempla la conformación del Comité Nacional de Convivencia Escolar y los Comités Municipales, Distritales y Departamentales de Convivencia Escolar. El comité tiene entre sus funciones la formulación de recomendaciones para el "adecuado desarrollo, complementación y mejoramiento de la ruta de atención integral en los 
establecimientos educativos en el marco del Sistema Nacional” (Ley 1620, 2013, art. 8).

Los planteles educativos están en el deber de contar con un sicólogo y docentes formados en instrumentos y rutas para detectar y atender a los menores en situación de riesgo de abuso sexual infantil. Cuando un docente o cualquier otro miembro de una institución educativa tiene conocimiento de un presunto caso de abuso sexual, este debe ponerlo en conocimiento del orientador psicosocial quien estudiará el caso hará un diagnóstico. Según lo que encuentre llamará al acudiente, se establecerán compromisos con los padres y hará el respectivo seguimiento. Si el hecho denunciado, el contexto en que este tiene lugar o los daños físicos y psicológicos causados al menor son de tal gravedad que exceden la competencia misional del plantel educativo, el rector activa la "ruta de atención integral para la convivencia escolar" de la que trata la Ley 1620 del 2013, y dará traslado del caso a la entidad competente.

\section{CONCLUSIONES}

Los datos estadísticos de Medicina Legal de los últimos cuatro años arrojan que más del $85 \%$ de los delitos sexuales reportados tuvieron por víctimas a niños, niñas y adolescentes. Se confirma además lo que señala la literatura especializada internacional sobre la materia, que el agresor es predominantemente de género masculino, mientras la víctima es mayoritariamente de género femenino. Asimismo, se encuentra que en la mayoría de los casos de abuso sexual infantil el agresor es un miembro del grupo familiar o una persona muy cercana a la familia.

Colombia ha suscrito todos los instrumentos internacionales de Derechos Humanos para la protección de los menores y los ha incorporado en su ordenamiento jurídico interno. Sobresalen en la materia el Código de la Infancia y la Adolescencia de 2006, el código penal, y la Ley 1146 de 2007. Esta última crea el "Comité Interinstitucional Consultivo para la Prevención de la Violencia Sexual y Atención Integral de los Niños, Niñas y Adolescentes Víctimas del Abuso Sexual", órgano que aglutina una pluralidad de enti- dades que trabajan por el bienestar de esta población como los ministerios de salud, educación y TICs, ICBF, Fiscalía, Procuraduría, Defensoría del Pueblo, Policía Nacional, entre otros.

Las cifras que presenta Medicina Legal ponen en evidencia que, pese a la normatividad existente para la prevención, tratamiento y sanción del ASI, la pluralidad de instituciones que vienen trabajando en la protección de los derechos de los menores, y los distintos programas que estas han venido implementando en la materia, el número de casos de ASI reportados en el país no ha disminuido y por el contrario ha aumentado.

El código penal colombiano presenta un progresivo aumento en las penas por delitos contra la integridad sexual de los menores. Si bien este enfoque no ha sido eficaz, ya que no han logrado disminuir el número de casos de ASI reportados anualmente, sí pone en evidencia la toma de conciencia cada vez mayor por parte de la sociedad de la gravedad de la problemática y de la necesidad de tomar medidas para remediarla.

Son diversas las estrategias para la prevención del abuso sexual infantil que se han venido adoptando en el país como los programas “Abre tus Ojos” de la Policía de Infancia y Adolescencia, y "Generaciones con bienestar" del ICBF. Sin embargo, estos esfuerzos no han logrado diezmar la problemática. Los pobres resultados en la materia pueden deberse a que, en la práctica, la política pública contra el maltrato infantil en general, y en particular contra el ASI, ha estado orientada principalmente a la promoción de la denuncia más que a la prevención del delito como tal.

En los colegios, la cátedra en sexualidad ha estado dirigida principalmente a los adolescentes y no a los menores más jóvenes. En muchas ocasiones esta cátedra se ha confundido con la cátedra de anatomía, la cual persigue fines diferentes. Más allá del conocimiento del cuerpo, se requiere desarrollar habilidades en el menor que le permitan diferenciar entre los acercamientos y contactos apropiados e inapropiados, identificar cuando se está en presencia de un abusador y saber cómo actuar y a quién acudir en dicho caso. 
Las políticas públicas contra el ASI se han encaminado más a atacar sus manifestaciones que sus causas. Estas políticas no están orientadas a atacar los principales factores de riesgo aquí estudiados como problemas de salud mental, alcoholismo y drogadicción, condiciones de pobreza, desigualdad de género, e incluso conflicto armado y desplazamiento forzado.

\section{Referencias}

Acuña, M. (2014). Abuso sexual en menores de edad: generalidades, consecuencias y prevención. Medicina legal de Costa Rica, 31(1), 57-69.

Almonte, C., Insunza C. \& Ruiz, C. (2002). Abuso sexual en niños y adolescentes de ambos sexos. Revista chilena de neuro-psiquiatría, 40(1), 22-30.

Barudy, J. (1998). El dolor invisible de la infancia. Una lectura ecosistémica del maltrato infantil. Barcelona, España: Editorial Paidós.

Berlinerblau, V. \& Taylor, E. (2003). Abuso sexual: evaluación psiquiátrica forense en denuncias de niños. Cuadernos de Medicina Forense, 2(2), 33-42.

Canesto, D. (2017). Exámenes medicolegales por presunto delito sexual. Colombia, año 2017. Forensis datos para la vida, 19(1), 302-348.

Cifuentes, S. (2018). Exámenes médico legales por presunto delito sexual. Colombia, 2018. Forensis datos para la vida, 20(1), 229-266.

Congreso de Colombia (12 de julio de 2018). Por medio de la cual se establece el régimen de inhabilidades a quienes hayan sido condenados por delitos sexuales cometidos contra menores, se crea el registro de inhabilidades y se dictan otras disposiciones. [Ley 1918 de 2018]. DO: 50.652.

Congreso de Colombia (15 de marzo de 2013). Por la cual se crea el Sistema Nacional de Convivencia Escolar y Formación para el Ejercicio de los Derechos Humanos, la Educación para la Sexualidad y la Prevención y Mitigación de la Violencia Escolar. [Ley 1620 de 2013]. DO: 48.733.

Congreso de Colombia. (10 de julio de 2007). Por medio de la cual se expiden normas para la prevención de la violencia sexual y atención integral de los niños, niñas y adolescentes abusados sexualmente [Ley 1146 de 2007]. DO: 46.685 .

Congreso de Colombia. (12 de julio de 2013). Por medio de la cual se dictan disposiciones acerca de la entrevista y el tes- 
timonio en procesos penales de niños, niñas y adolescentes víctimas de delitos contra la libertad, integridad y formación sexuales. [Ley 1652 de 2013]. DO: 48.849.

Congreso de Colombia. (21 de julio de 2009). Por medio de la cual se adiciona y robustece la Ley 679 de 2001, de lucha contra la explotación, la pornografía y el turismo sexual con niños, niñas y adolescentes. [Ley 1336 de 2009]. DO: 47.417.

Congreso de Colombia. (23 de julio de 2008). Por medio del cual se modifican algunos artículos del Código Penal relativos a delitos de abuso sexual [Ley 1236 de 2008]. DO: 47.059.

Congreso de Colombia. (24 de julio de 2000). Código Penal. [Ley 599 de 2000]. DO: 44.097.

Congreso de Colombia. (3 de agosto de 2001). Por medio de la cual se expide un estatuto para prevenir y contrarrestar la explotación, la pornografía y el turismo sexual con menores, en desarrollo del artículo 44 de la Constitución. [Ley 679 de 2001]. DO: 44.509 .

Congreso de Colombia. (7 de julio de 2004). Por la cual se modifica y adiciona el Código Penal. [Ley 890 de 2004]. DO: 45.602 .

Congreso de Colombia. (8 de noviembre de 2006). Código de la Infancia y la Adolescencia [Ley 1098 de 2006]. DO: 46.446.

Constitución política de Colombia (1991). 2da Ed. Legis.

Corte Suprema de Justicia, Sala de Casación Penal. (11 de julio de 2018) Sentencia SP2709-50637. [MP Patricia Salazar Cuéllar]

Departamento Administrativo de la Función Pública. (9 de mayo de 2013). Por el cual se reorganiza el Sistema Nacional de Bienestar Familiar, se reglamenta el inciso primero del artículo 205 de la Ley 1098 de 2006 y se dictan otras disposiciones. [Decreto 936 de 2013]. DO: 48.786.

Gil, J. \& De Manuel, C. (2019). Abuso sexual infantil. Congreso de Actualización en pediatría. 3(1). p. 267-275.

Gómez, E., Cifuentes, B. \& Sieverson, C. (2010). Características asociadas al abuso sexual infantil en un programa de intervención especializada en Santiago de Chile. SUMMA Psicológica UST, 7(1), 91 - 104.

Gonzaga, L. (2015). Factores de riesgo asociados al abuso sexual en niños y adolescentes. División médico legal I Utcubamba amazonas. (Trabajo de Maestría, Universidad) Nacional de Cajamarca.

González, E., Martínez, V., Leyton, C. \& Bardi, A. (2004). Características de los abusadores sexuales. Revista Sogia, 11(1), 6-14.

González, J. (2007). Informes periciales por presunto delito sexual. Colombia, 2007. Forensis datos para la vida, 9(1), 141-178.

Instituto Colombiano de Bienestar Familiar ICBF. (2018). Portafolio de cooperación 2018-2019. Recuperado de: https://www. icbf.gov.co/sites/default/files/portafolio_2018_vl_0.pdf

Isaza, M., Alzate, L., \& Santander, L. (2007). Proyecto para la prevención del abuso sexual de niñ@s y adolescentes en el programa “apoyo a la integración” en la fundación integrar 2007. (Trabajo de grado, Especialización en Salud Mental). Universidad CES.

Lameiras, M., Carrera, M. \& Failde, J. (2008). Abusos sexuales a menores: estado de la cuestión a nivel nacional e internacional. Revista D'Estudis de la Violencia, 6 (julio-noviembre), 1-23.

ONU Mujeres (2010). Causas, factores de riesgo y de protección. $O N U$. Recuperado de: http://www.endvawnow.org/es/articles/300-causas-factores-de-riesgo-y-de-proteccin.html

Organización de las Naciones Unidas (194). Declaración universal de derechos humanos. Resolución 217 A (III)

Organización de las Naciones Unidas (1989). Convención sobre los derechos del niño. Resolución 44/25.

Organización de las Naciones Unidas (2000a). Protocolo facultativo de la Convención sobre los Derechos del Niño relativo a la venta de niños, la prostitución infantil y la utilización de niños en la pornografía. Resolución 66/138. 
Organización Internacional del Trabajo OIT (1999). Convenio 182 sobre las peores formas de trabajo infantil.

Organización Mundial de la Salud (2009). Prevención del maltrato infantil: Qué hacer y cómo obtener evidencias. Ginebra: Ediciones de la OMS.

Policía Nacional de Colombia (2018). Informe de Gestión 2018. Bogotá D.C.: Policía Nacional.

Policía Nacional de Colombia (2019). Informe de Gestión 2019. Una Policía para la gente. Bogotá D.C.: Policía Nacional.

Presidencia de la República (2018). Política nacional de infancia y adolescencia 2018-2030. Recuperado de: http://snbfsociedadcivil.aldeasinfantiles.org.co/files/PN2018-2030.pdf

Presidencia de la República (2019). Política Marco de Convivencia Seguridad Ciudadana. Bogotá D.C.: Ministerio de Defensa Nacional. (3 de diciembre de 2007). Por el cual se crea la Comisión Intersectorial para la prevención del reclutamiento y utilización de niños, niñas, adolescentes y jóvenes por grupos organizados al margen de la ley. [Decreto 4690 de 2007]. DO: 46831.

Presidencia de la República (2019). Política Marco de Convivencia Seguridad Ciudadana. Bogotá D.C.: Ministerio de Defensa Nacional.

Ricaurte, A. (2016). Exámenes medico legales por presunto delito de abuso sexual. Colombia, 2016. Forensis datos para la vida, 18(1), 351-400.

Soria, M. \& Hernández, J. (1994). El agresor sexual y la víctima. Barcelona, España: Marcombo. 
